\title{
Effect of Education and Emotional Intelligence on Consumers' Impulsive Buying Behavior
}

\author{
HUSSIN JOSE HEJASE \\ Al Maaref University, Faculty of Business Administration, Beirut, Lebanon \\ Email: hhejase@mu.edu.lb \\ YOLANDE SKAFF \\ Modern University of Business and Sciences, Beirut, Lebanon \\ DIANA EL SKAFF \\ Medical Surgical Unit, American Hospital, Dubai, United Arab Emirates \\ ALE J. HEJASE \\ Al Maaref University, Faculty of Business Administration, Beirut, Lebanon
}

\begin{abstract}
Today, marketing has become highly competitive across the industry, and understanding consumers' behavior has become a challenging task for the marketers. In strategic marketing planning, consumer behavior is an integral part of said process as the consumer plays the role of the user, the buyer and the payer. The behavior of the consumers changes as the factors that affect the consumer's behavior change. The goal of this research is to examine the effect of education on consumers' impulsive buying behavior. Data is collected using a 30-question questionnaire to test the respondents' impulsive buying behavior, their attitude to impulsive buying, and their education level and Emotional Intelligence. The sample size is 200, of which 184 are valid. Statistical Product and Service Solutions (SPSS) is used to analyze the acquired data to discern the correlation between the level of education and impulsive buying behavior.
\end{abstract}

Keywords: Impulsive Buying, Demographic Factors, Education, Lebanon.

\section{Introduction}

Rook (1987) defines impulsive buying as the unplanned and sudden purchases that are triggered on the spot, and are accompanied by pleasure and excitement. Several other definitions were given for impulsive buying; for instance, Beautty \& Ferrell (1998) define it as a sudden and immediate purchase decision made inside a store with no previous intentions to buy the specific product. Further, impulsive buying is explained as the urge to purchase a product without the consideration of the consequences of the decision to buy it (Rook, 1987; Kacen \& Lee, 2002). It occurs when an item that was not pre-planned is purchased (Park, Iyer, \& Smith, 1989).

To have a clear and an upfront idea of impulsive buying, a special interview was conducted with a professional female on the topic; it resulted in the following short case study which is used as a prototype that represents many Lebanese females and most possibly others. The name is kept confidential. 
"She is a 34-year old female, living in Dubai, a Registered Nurse by training, and works as a Nurse Manager at the American Hospital of Dubai. She holds a Bachelor of Science in Nursing and a Master in Business Administration. She is labeled by her family 'an impulsive buyer', but she begs to differ.

She hates shopping, and she rarely does unless she has to. Her behavior in this matter is controversial and has evolved over time. When she started working and earning (in Lebanon), she wanted to get whatever she had wished for. However, she kept her distance and kept busy at work and other commitments. When her status became a bit better, she visited the malls every now and then, and always bought without thinking. Sometimes she bought things that she knew she will never use, and ended up distributing these goods to whomever needed them. Shortly after, she started inhibiting herself from over buying and over spending by not shopping at all. However, she still bought without thinking whenever she had an occasion-cloths, gifts, perfume, and especially make up.

Her behavior kept on changing, or adapting to her lifestyle; she started putting in the cart whatever she saw and liked; however, before paying, she went over the items she had and refrained from buying some of them. This method helped her in limiting the habit, but did not curb her over spending whims. When she moved to Dubai and became totally independent, she had to put limitations since she had to watch out and manage her expenses. She started by purchasing essential things for her house to make it "homey". She thought things through and analyzed whether the bought items were essential, necessary or complimentary. She got the essentials and then the necessary... She kept this pattern for a year and few months. She then moved to another house; it needed more stuff... It was necessary to make some changes, and she bought complementary furniture that was fairly expensive, though not necessary or urgent at that time, but she never regretted having bought them. This habit totally stopped afterwards; she stopped buying. As for the clothes, it posed a dilemma to her; especially since she hates to get to the shopping center and try on clothes. Usually, she goes once in a semester and collects items she likes, tries them on and gets everything that fits at once.

Her overspending habit did not stop when it came to her family, especially her kid nieces. Actually it increased. Whenever she is somewhere and she sees things that can be interesting or nice for any of them, she just buys the items; for instance, for the recent birthday of one of them, she went to get the gifts for herself, her mother and her sister. She just got whatever she felt like. She still does not know how much she had paid and she does not care.

Basically, she consciously pays big bills on herself every now and then, to just get what is necessary or urgently needed. Now, she has channeled her urge to over-spend into saving strategies which are working bit by bit: buying gold or saving the amount aside."

Consequently, several questions arise from the aforementioned case:

- What is an impulsive buying behavior?

- What are the types of impulsive buying behaviors?

- What are the general factors that affect customers' buying behavior?

- More specifically, how are the consumers' educational level and Emotional Intelligence related to the impulsive buying behavior?

- And finally, how much are the citizens of the MENA region in general, and in Lebanon in particular, aware of impulsive buying behavior and its characteristics

\section{Problem Statement}

Marketing as a science, with all its disciplines, has been implemented to investigate the causes, factors, action mechanisms and consequences of consumer behavior; much has been discovered and achieved in this aspect. However, marketing theories and practices are still far from explaining all the aspects of 
consumer behavior; hence, due to its discernable diversity and multitude factors, consumer behavior is the most complex contemporary issue of marketing theory and practice (Žnideršić, Grubor, \& Marić, 2014).

This study aims to explain the phenomenon of impulsive behavior by indicating factors and clarifying the principle of impulsive behavior. Specifically, this research examines the effects of education per se and Emotional Intelligence on consumers' impulsive behavior; these two factors that were masked by most of the researches done previously.

\section{Research Dilemma}

Market researchers have had a persistent interest in the pervasive phenomenon of consumers' impulsive behavior, but many questions about impulsive purchase behavior still remain unanswered (Rook, 1987). Although the topic has received research interest, such as that of Abratt and Goodey (1990) - South Africa, and that of Kacen \& Lee (2002) - the United States, little is known about how education level influences unplanned purchases in the MENA (Middle East and North Africa) region, precisely in Lebanon, where little to no studies have been done on this matter.

\section{Research Objectives}

The primary research objective is to determine the impact of education and emotional intelligence on consumers' Impulsive Buying Behavior (IBB). The secondary objective of this study is to determine the impact of education and Emotional Intelligence on the Lebanese consumers' IBB.

\section{Research Questions}

Accordingly, the following specific research questions arise:

- How does education affect the customers' impulsive buying behavior?

- What is Emotional Intelligence and how does it affect the IBB?

- How do the education level and Emotional Intelligence affect the Lebanese consumers' impulsive buying behavior?

\section{Research Significance}

The economic relevance of impulsive buying behavior has assumed significance with the opening up of the international markets, the enrichment of the consumer society and the creation and spread of the mall culture (personal communication, Dr. Bassam Hamdar, economist, September 14, 2018). Impulsive buying behavior is better understood by examining the impulsive buying tendency that prompts such behavior; moreover, and since consumers' behavior differs across cultures, it is vital and of utmost importance to study the effect of education on these tendencies and behaviors. Also, manufacturers and retailers need information on the extent that education influences consumers' purchasing behavior so as to differentiate their stores from those of competitors and gain competitive advantage through devising more effective promotion and marketing strategies.

\section{Literature Review}

\section{Marketing, Consumer Behavior and Impulsive Buying}

Marketing as a science, with all its inferred disciplines, has endeavored ever since its development to examine the causes, components, action mechanisms and results of consumers' behavior; however, in spite 
of the fact that much has been found and accomplished in this perspective, marketing theories and practices are still far from clarifying all the perspectives of consumers' behavior (Gaurav \& Sahu, 2017). Consumer behavior is the foremost complex issue of marketing theory and practice due to its stamped diversity and a huge number of variables that have a combined effect on it, in more or less assorted ways, depending on the business event (Žnideršić, Grubor, \& Marić, 2014).

Researchers have been extensively seeking to reach an understanding as to how consumers behave in the market; they have widened the scope of their studies on consumption trends/characteristics, to extend from disciplined buying to compulsive spending (Lee \& Mysky, 2004), including factors that differentiate "good" consumption from "bad" consumption habits. Due to the aforementioned consumption trends/characteristics, researchers have been focusing on the destructive consequences of consumers' impulsive buying behavior on self, family, and society (Faber \& O'Guinn, 1992). In the same vein, Žnideršić, Grubor, \& Marić (2014) state that marketing researchers have been attempting, for decades now, to discover all the aspects of consumers' impulsive buying behavior; the researchers' target is to investigate the types and categories of products/goods that may induce impulsive buying behaviour, and characterize the companies' marketing offer and marketing techniques based on the aforementioned discoveries. In addition, several researches have been conducted in the field of impulsive buying; they ranged from defining Impulsive Buying Behavior (IBB) to classifying it into several sub-categories (Kacen \& Lee, 2002). Consumer impulsive buying is an extensively known phenomenon in the US (Kacen \& Lee, 2002; furthermore, studies investigated the cause of consumers' impulsive buying behavior and classified these causes according to individual characteristics, demographics, Emotional Intelligence, cultural, situational characteristics and others (Mihic \& Kursan, 2010). However,Workman \& Paper (2010) support the fact that additional investigations are vital to understand the phenomenon of Impulsive Buying Behavior, which had been defined by Faber \& O'Guinn (1992, p. 155) as "a response to an uncontrollable drive or desire to obtain, use, or experience a feeling, substance, or activity that leads and individual to repetitively engage in a behavior that will ultimately cause harm to the individual and/or others."

After extensive reading, the researchers of this paper agree with the following comprehensive definition: "Impulsive buying is a sudden, compelling, hedonically complex purchasing behavior in which the rapidity of the impulse purchase decision process precludes thoughtful, deliberate consideration of all information and choice alternatives" (Kacen \& Lee, 2002, p. 163). In other words, it is considered to be a more exciting, less cautious, and more seductive buying behavior; it is attributed to almost $70 \%$ of all perchasing decisions (Heilman, Nakamoto, \& Rao, 2002). Solomon (2002) and Vohs \& Faber (2007) support the aforementioned definition by stating that impulsive buying is an unplanned, sudden, and spontaneous impulse to buy; an act that doesn't consider careful evaluation of product and purchase consequences. While Karbasivar \& Yarahmadi (2011) handle impulsive buying in a diffirent manner and define it as a state where consumers' focus is on satisfying their powerful needs, neglecting the real problem, which is to be resolved in a higher quality manner. Furthermore, Shahjehan, Qureshi, Zeb \& Saifullah (2012) contend that before providing a definition, one needs to begin by defining impulsivity as a personality trait characterized by a tendency to act without provision, make quick decisions, and fail to recognize the consequences. They describe Impulsive Buying Behavior (IBB) as a "spontaneous or sudden desire to buy something, and when compared to more contemplative approaches to decision making, is considered emotional, reactive, and prone to occur with diminished for the consequences" (p. 2188). In the same vein, Rana \& Tirthani (2012) state that impulsive buying is a disruption of the normal decision making; it occurs when "a customer sees a product in the store and purchases it with little or no deliberation due to a strong urge to possess the item" ( $p$. 145). Whereas impulsive buying is defined as "a sudden, compelling, hedonically complex purchase behavior in which the speed of the impulsive purchase decision on precludes any thoughtful, deliberate consideration of alternatives or future implications" (Masouleh, Pazhang, \& Moradi, 2012, p. 1054). Similarly, Žnideršić, Grubor, \& Marić (2014) describe impulsive buying as the customers' deviation from standard and rational behavior to satisfy their physiological and personal psychological needs. 
To sum up, impulsive buying arises when a costumer goes to buy a product and then he/she buys another product which he/she did not intend to buy (Howlett, Kees, \& Kemp, 2008; Verplanken \& Sato, 2011).

Hence, it is deduced from the aforementioned definitions the following characteristics of customers' buying behaviors (Rana \& Tirthani, 2012):

- The feeling of an irresistible drawing/compelling force emitted by the product

- An immediate sense of ownership of the product

- A disregard of any negative consequences of the purchase decisions

- A feeling of excitement in the heat of the moment

- A dilemma between control and indulgence

\section{Types and Factors of Impulsive Buying}

Han, Morgan, Kotsiopulos, \& Kang (1991) and Etzioni (1999) have initially enumerated four types of Impulsive Buying which were adopted by others, namely:

1) Pure Impulse Buying: It is when customers buy unplanned products which appeal to them, and had no intention of buying initially (Ferber, 1973).

2) Reminder Impulsive Buying: It is the process in which customers' need for an item is triggered when they see this item or are reminded of it (Lee \& Kacen, 2008).

3) Suggestion Impulsive Buying: It is defined as " the process of buying those products which customers see first time in the store and realize that they might need" (Nadeem, Akmal, Omar, \& Mumtaz, 2016, p. 3; Bell, Crosten, \& Knox, 2011)

4) Planned Impulsive Buying: It occurs when customers visit the market with no plan to buy any special product, but to check promotions and deals (Agee \& Martin, 2001; Madhavaram \& Laverie, 2004)

Researchers also focused on the factors that influence impulse buying and consumers' behavior and differentiated two main factors. Herein is a consise list of said factors as perecieved by Chen (2008, p. 155), Karbasivar \& Yarahmadi (2011, p. 175), Yang, Huang, \& Feng (2011, p. 275), and Gaurav \& Sahu (2017):

- External impulsive purchase factors are fully controlled by companies to provoke the impulsive buying mechanism; these factors include

- Store appearance

- In-store displays

- Shopping environment

- Price discounts and point-of-sale promotions

- Internal impulsive purchase factors can be influenced by the company, but are solely controlled by the consumer; they include

- The consumer's personality traits

- The consumer's emotional and affective state

- Demographic factors

- Profession, educational level, marital status, social position etc.

What concern us in this research are the internal impulsive prurchase factors, especially the consumers' affective responses; hence, the effect and characteristics of these responses are discussed. Affects reflect the consumers' immediate and automatic response to stimulias delineated herein (Maricić, 2011, p. 133): 
- Effect of affects on consumers' behavior:

- "Positive mood accelerates the consumer education process and shortens the decision-making time when choosing products or services"

- Strengthened mood favors products with positive associations

- Emotions triger consumer's motivation to buy

- Characteristics of affect-driven response:

- These responses are either beyond or under slight control of the consumer

- They include consumers' physiological responses

- They are learnt

It is of utmost importance to discuss, at this stage, the process that consumers undergo while buying impulsively. Coley \& Burgess (2003, p. 283) claim that instantaneous effect of external and internal stimuli results in positive shopping emotions and directs consumers' moods, shadowed by a powerful need and desire to buy that is irresitible, leading to the emergence of impulsive-driven behavior. This statement is also upheld by Žnideršić, Grubor \& Marić (2014) who describe impulsive purchases as characterized by abrupt unplanned urge to buy, which can be opposite to the consumer's earlier behavior, followed by a state of psychological imbalance and loss of control over the consumer's own behavior, occurrence of psychological struggle caused by the analysis of satisfaction and significances, decrease in the consumer's cognition, and lastly, appearance of impulse-driven behavior.

Several researchers linked consumers' impulsive buying behavior to emotions and Emotional Intelligence; Youn \& Faber (2000) indicate that consumers involve in impulsive buying behavior whenever they experience a strong urge to buy because they are more concerned about their affective state (emotions) than their cognitive state (logic); these emotions might include an "irresistible urge to buy, mood management, amusement, delight and joy" (Coley \& Burgess, 2003). Furthermore, Hanna \& Wozniak (2001), Lavack, \& Kropp (2008), Maricici (2011), Silvera, and Sarki, Bhutto, Arshad, \& Khuhno (2012) state that the consumer while experiencing impulsive buying driver, has little time for decision-making and that there is a limited existence or total lack of cognitive effort in decision making; the latter is impacted by emotional appeals.

\section{Education and Emotional Intelligence}

Of special interest in this research are the demographic factors that influence the customers' IBB; more specifically, the educational level of these customers. The educational level is considered to be a significant factor in customers' impulsiveness (Bressolles, Durrieu, \& Giraud, 2007). Education make customers think, observe and explore the products more; Hugar \& Kumar (1996) concluded that the educational level of the consumers has an effect on the quantity and frequency of purchase, in that education inhibits consumers from making particular purchases. Bruyneel, Dewitte, Vohs, \& Warlop (2006) argue that customers with higher educational levels have more financial knowledge than common people. These customers spend their money where they could benefit from purchased products; they prefer planned shopping (Manzur, Olavarrieta, Hidalgo, Farías, \& Uribe, 2011). It is believed that the educational level has a negative relationship with impulsive buying (Rana \& Tirthani, 2012; Bashar, Ahmad, \& Wasi, 2012; Shahjehan, Qureshi, Zeb, \& Saifullah, 2012; Nadeem, Akmal, Omar, \& Mumtaz, 2016). More specifically, the most professional courses offered in business schools and engineering institutes train the consumers to develop deep understanding of the market, product, brand and utility; this leads to an increase in their awareness and their ability to perform a particular purchase (Khan \& Chawla, 2014). In other words, educated consumers are more influenced by their position and place in the society; however, this does not cancel another inherent truth ingrained in one's social behavior, namely that illiterates can control their excesses and would only spend money on products initially thought and planned for (Ekeng, Lifu, \& Asinya, 2012). Conversely, if education is negatively related to impulsive buying, then why some educated people are still impulsive buyers? This is mainly caused by their lack of Emotional Intelligence (Xiofang \& Miller, 2003); it is believed that consumers' Emotional Intelligence (CEI) positively moderates the relationship between 
educational level and IBB (Kidwell, Hardesty, Murtha, \& Sheng, 2011; Rana \& Tirthani, 2012; Nadeem, Akmal, Omar, \& Mumtaz, 2016).

Back to the case introduced earlier; the person of interest shows many types of impulsive buying behavior. For instance, she moved from being a pure impulsive buyer to a reminder impulsive buyer, especially in situations that concerned her interest (clothes and home appliances). However, she is still a pure impulsive buyer when it comes to buying for her loved ones.

Additional factors that affect the consumers' buying behavior are enumerated by different researches:

- Consumers' mood and emotions (Weinberg \& Gottwald, 1982; Rook \& Gardener, 1993; Tice, Bratslavsky, \& Baumeister, 2001)

- $\quad$ Trait buying impulsiveness (Rook \& Fisher, 1995)

- $\quad$ Culture (Mihic \& Kursan, 2010)

- $\quad$ Store environment (Awan \& Abbas, 2015)

- Consumers' income (Ekeng, Lifu, \& Asinya, 2012; Awan, Hassan, \& Shahid, 2014)

- Demographic factors (Bellenger, Robertson, \& Hirschman, 1978; Wood, 1998; Mai, Lantz, \& Loeb, 2003); Rook \& Fisher (1995) specifically confirm that not only age, but the shoppers' gender and educational level are essential factors in IBB.

In this research, the focus is on the effect of the demographics factors on the impulsive buying behavior, more specifically, the effect of education and Emotinal Intelligence. Bashar, Ahmad and Wasi (2012) investigated the effect of demographic factors on consumers' impulsive buying behavior; the results show that educational qualifications have minimal association with implusive behavior. In addition, the study of Sharma \& Kaur (2015) used the Chi-squared test between demographic variables and impulsive buying behavior; this test reveals that education has no significant relationship with impulsive buying behavior. More specifically, this study shows that there is very low positive correlation between education and IBB.

On the whole, it is relevant to suggest that study into the effect of education on consumers' impulsive buying behavior has received unclear and limited attention by various past studies in the related disciplines, particularly in the marketing field. Based on this, much attention is required; as such, this study seeks to focus and contribute to advance knowledge of education and consumer's impulsive buying behavior; thus, the importance and value of this study.

\section{Lebanon: Brief Economic Facts}

This research is carried out in Lebanon, a small Middle Eastern country which enjoys a free-market economy and a strong laissez-faire commercial tradition (CIA, 2018a). Table 1 shows key economic facts about Lebanon's economic state (globaleEDGE, 1994-2017); of interest in this table are the maked sections: the income level is considered to be an upper middle income, the unemployement force forms $6.29 \%$ by the year of 2017 . Also, this country's imports are greater than its exports. It is worth mentioning that $79 \%$ of the GDP is for services.

In 2017, the population in Lebanon consisted of $6,229,794$ with a growth rate of $-1.1 \%$ (CIA, 2018b). In 2009-2010, scholars, university students and students in vocational and technical educational institutions represented about $32 \%$ of the total population of Lebanon; overall, the number of school children is approximately 5 times more than the number of university students (Yaacoub \& Badre, 2012). In addition, according to Banque BEMO (2014; cited in Hejase \& Alaeddine, 2017) "a literacy rate exceeding 90\% amongst adults and $98.70 \%$ among youth. Lebanon exhibits tremendous gains in terms of more equitable access to formal education: The literacy rate among youth females surpass that of youth males, countervailing the dominance of literate male adults over female adults at $93.50 \%$ and $86 \%$ " (p. 27). Only $53 \%$ of the population of Lebanon aged 15 years and above holding university degree are in employment, the remaining are either inactive or unemployed (Unicef, 2013). 
Table 1: Lebanon's Key Economic Facts

\begin{tabular}{|l|l|}
\hline Income Level (by per capita GNI) & Upper Middle Income \\
\hline Level of Development & Developing \\
\hline GDP, PPP (current international \$): & USD 85.95 billion (2016) \\
\hline GDP Growth (annual \%): & $2.00 \%(2016)$ \\
\hline GDP per capita, PPP (current international \$): & USD 14,308.75 (2016) \\
\hline External debt stocks, total (DOD, current USD): & USD 31,960,710,000.00 (2016) \\
\hline Manufacturing, value added (\% of GDP): & $9.06 \%(2016)$ \\
\hline Current account balance (BoP, current USD): & - USD 9.86 billion (2016) \\
\hline Inflation, consumer prices (annual, \%): & $-0.81 \%(2016)$ \\
\hline & \\
\hline Labor force, total: & $2,207,595(2017)$ \\
\hline Unemployment, total (\% of total labor force) (modeled ILO estimate): & $6.29 \%(2017)$ \\
\hline Import of goods and services (current USD): & USD 23.37 billion (2016) \\
\hline Exports of goods and services (current USD): & USD 12.64 billion (2016) \\
\hline
\end{tabular}

These data will be used as a guide in subsequent analysis of the primary data collected from the implemented questionnaire.

\section{Research Methodology}

\section{Research Philosophy}

"Research philosophy is the way to go about doing a research" (Hejase \& Hejase, 2013, p. 77). A research philosophy includes the set of beliefs as to the nature of the reality being investigated (Bryman, 2012); i.e., the underlying definition of the nature of knowledge.

In this research, the researchers chose the positivism philosophy whereby the researcher acts as an objective observer that describe reality. In other words, the researchers are independent of this research, i.e. had minimal interaction with the research participants (Mkahal, 2016).

\section{Research Strategy}

The strategy implemented by the researchers is the questionnaire-survey method; this method ensures the collection of a large amount of data from a sizable population. The data are analyzed quantitatively using descriptive and inferential statistics (Saunders, Lewis, \& Thornhill, 2007). The researchers are interested in collecting the data from the Lebanese community of different educational levels. The survey is discussed elaborately in the following parts.

\section{Research Design}

This research is an applied quantitative one because it emphasizes the socially constructed nature of reality. It is concerned with recording, analyzing and attempting to uncover the deeper meaning and significance of human behavior and experience that affect customers' impulsive buying behavior in Lebanon. The main interest is in gaining a rich and complex understanding of consumers' buying behaviors and how the said consumers are affected by their level of education. In addition, this research is an exploratory research in nature; it is conducted to assimilate the influence of education on IBB in Lebanon, and will be used as a guide for further detailed and quantitative researches. This research follows the deductive approach since it works from the more general to the more specific. The factors that influence the consumers' IBB are studied first, then the educational element of the Lebanese population is focused on. 


\section{Data Collection}

Considering the nature of the research, the study made use of both primary and secondary data. Secondary data is accessed through the use of published journal articles, text books and the Internet. While the primary data is collected via a survey questionnaire that was posted online, and was distributed to people of different socio-economic and educational levels, and who were chosen at random. The questionnaire was also distributed in some institutions, universities and published online for the purpose of having a wide and diverse sampling. Also, the questionnaire was translated into Arabic, the native language, so that the researchers may reach a wide variety of the population. 200 valid questionnaires were collected.

\section{Survey Questionnaire Design}

This research is conducted using a simple structured questionnaire that consists of 37 questions distributed among four sections that cover the respondents' impulsive buying behavior, attitude towards impulsive buying, the effect of education and Emotional Intelligence on impulsive buying behavior, and demographical questions.

The questionnaire begins with a passage that informs the participant of the objective and transparency of the said questionnaire, and the topics discussed. Section 1 includes eight questions using a four-point Likert scale (4= Frequently and 1= Never), and are to assess the respondents' habits in buying and shopping. Section 2 includes six questions using five-point Likert scale questions (5= Strongly Agree and $1=$ Strongly Disagree) that focus on the respondents' attitude towards impulsive buying. Section 3 has 16 questions to assess the respondents' Emotional Intelligence and level of education, also using a five-point Likert scale. Section 4 uses multiple choice questions and dyadic questions pertaining to demographics of the sample including age, gender, educational level, major, and basic yearly income.

One final open-ended question is designed to motivate respondents to add to the questionnaire any remarks on related points that have not been discussed. In addition, the questionnaire was translated to Arabic so that it can reach a larger section of the population who have law educational levels.

\section{Sampling}

The target sampling population for this study is all the Lebanese working population, the main purpose of this study is to understand the effects of education on the consumers' buying behavior of said population. Therefore, any Lebanese buyer or purchaser, willing to participate was considered in this research.

The data was collected over a period of one month; the Arabic and English versions of the questionnaire were shared on social media, and printed versions were distributed in different universities and corporations to different employees. The total number of acceptable questionnaires is 184 out of 200. 12 questionnaires were rejected because they were wrongly filled, and 4 were incomplete. Therefore, the response rate is $92 \%$, which is an acceptable percentage for such a study.

\section{Descriptive Analysis}

All responses were entered to the SPSS version 23 program "Statistical Product and Service Solutions", an IBM product acquired by IBM in 2009 (Hejase \& Hejase, 2013, p. 58). The study is performed using exploratory statistics; data tables including frequency and percentage distributions and supported by their respective figures. Moreover, cross tabs and regression analysis are performed to study relationships between variables that may add value to the findings of the research. 


\section{Results and Findings}

The purpose of the current research thesis is to assess a sample of Lebanese respondents' impulsive buying behaviour, their attitude towards impulsive buying, and the impact of their education level and Emotional Intelligence on impulsive buying.

\section{Descriptive Analysis}

\section{Section 1: Respondents' Impulsive Buying Habits}

\section{Purpose of shopping}

The relation of shopping to the current respondents' mood is delineated as follows:

IBB is described as a "spontaneous or sudden desire to buy something", and is accompanied by pleasure and excitement. Results show that $14.1 \%$ of the respondents go shopping frequently to change their mood; $35.3 \%$ occasionally does so, giving a cumulative of $49.5 \%$ for occasionally and frequently. $32.1 \%$ of the respondents state that shopping rarely lightens their moods, and $18.5 \%$ never recourse to shopping to change their moods. Does the high percentage of $49.5 \%$ indicates lack of education, or Emotional Intelligence vis-à-vis the impulsive shopping?

\section{Feeling of happiness after the purchasing of an unplanned item}

Results show an interesting positive impact on the respondents' feelings of happiness when they buy an unplanned item. 27.2\% responded with "Frequently" and 34.2\% with "Occasionally", for a cumulative of $61.4 \%$ which is more than half of the sample of respondents. $29.9 \%$ responded with "Rarely" and only $8.7 \%$ answered "never" to the question. It is true that shopping might affect the mood positively; however, the answers to the question show that shopping has a positive impact even when the item being purchased is not planned for. What would be the indication or meaning of this? Is there a correlation between feelings and the impulsive buying habit? Would that imply that $61.4 \%$ of the respondents have Pure Impulsive Buying habit?

\section{Feeling of Regret after an unplanned purchase}

Results show that only $9.8 \%$ frequently regret buying without a plan, whereas $28.8 \%$ occasionally does; $35.3 \%$ rarely regrets buying without a plan and $26.1 \%$ never does. The cumulative of "Frequently and Occasionally" is only $38.6 \%$, whereas $61.4 \%$ is rarely or never regretful. Thus, a happy feeling generated by an unplanned purchase is rarely followed by a feeling of regret, as per the respondents' responses.

\section{Control of the urge to buy when a good offer is seen}

Planned Impulsive Buying occurs when customers visit the market, with no plan to buy any special product, for the purpose of checking promotions and deals (Agee \& Martin, 2001). Results show that $17.4 \%$ frequently loses control when they see a good offer, $25.5 \%$ occasionally faces this difficulty, $36.4 \%$ rarely does, and $20.7 \%$ never does. $42.9 \%$ has difficulty controlling the urge to buy something when a good offer is displayed, leading to an assumption that the sample respondents have impulsive buying habits that are pure and not planned.

\section{Tendency to increase the intent to buy when promotions are offered}

Table 2 indicates that $60.3 \%$ of the respondents have no control on the amount of purchase of promotions 
that are offered; $25 \%$ frequently buys more when they see good deals; $35.3 \%$ occasionally does the same; $30.4 \%$ rarely buys more when they see good offers; and, $9.2 \%$ never does. These results are again reflective of the Planned Impulsive Buying; however, it contradicts the results of the previous question. This discrepancy makes us think that even though the minority of the respondents does not show a Planned Impulsive behavior; however, they directly exhibit Pure Impulses when surrounded by offers.

Table 2: When I see a good deal, I tend to buy more than I intended to buy

\begin{tabular}{|ll|c|c|c|}
\hline & Frequency & Percent & Valid Percent \\
\hline Valid & Frequently & 46 & 25.0 & 25.0 \\
& Occasionally & 65 & 35.3 & 35.3 \\
& Rarely & 56 & 30.4 & 30.4 \\
Never & 17 & 9.2 & 9.2 \\
Total & 184 & 100.0 & 100.0 \\
\hline
\end{tabular}

\section{Intent to visit malls}

Results show that $28.8 \%$ frequently visits malls and $50 \%$ occasionally does (cumulative of $78.8 \%$ ); whether or not frequenting malls has an effect on the IBB, it would be very interesting to study the correlation between these questions. $19 \%$ of the respondents rarely visit malls and only $2.2 \%$ never does.

\section{Buying something other than the intended}

Results also show that $21.7 \%$ frequently buys more than they had planned when they go shopping, and $28.3 \%$ occasionally ends up doing the same; whereas, $39.1 \%$ rarely does and $10.9 \%$ never does. The cumulative of $50 \%$ is indicative of either reminder IBB or suggestion IBB. $50 \%$ of the respondents can be part of the category of people who are reminded of the things they want when exposed to the items or when they think they need the items they see and buy them even if they are not on their shopping list.

\section{Money as obstacle to shopping}

Consumers' income is considered as a factor that affects the impulse buying behavior; respondents in this case opine that $10.9 \%$ frequently does not consider money as being an issue when they go shopping, and $35.3 \%$ occasionally does not consider money as obstacle to their shopping, $32.1 \%$ sometimes sees money as an issue, and $21.7 \%$ considers money as a main issue. $46.2 \%$ of the respondents have no problem of money; they are not inhibited by the availability of money or the lack of it, and will continue their shopping habit whether it is planned, pure, or reminder IBB.

\section{Section 2: Attitude towards impulsive buying}

Results show that $27.7 \%$ of the respondents agree with the statement "Just do it" when they go shopping, $28.3 \%$ is neutral, and $44 \%$ disagrees. The analysis of the question by itself does not explain the attitude towards IBB; it simply gives a glimpse of the respondents' description of IBB.

Results show that $19 \%$ of the respondents buy first and think later. $14.1 \%$ is neutral, and a cumulative of $66.9 \%$ does not have the impulse to buy just anything; they do think of the purchase that they are making. Hence, having purchasing impulses as shown in the section of habits to IBB, may be controlled as to what to buy; further correlation is needed to prove this theory.

Results show that $25.50 \%$ of the respondents agree on having no control as to what they buy, whereas $60.90 \%$ disagrees on being out of control over their purchasing abilities; however, $13.6 \%$ remains neutral. 
The results of this question and the one before are in agreement. The majority replied that they do think of their purchases first; they seem to have control of their behavior as well.

Table 3: Attitude towards impulsive buying

\begin{tabular}{|l|l|c|c|c|}
\hline No. & Statement & $\mathrm{A}$ & $\mathrm{N}$ & $\mathrm{D}$ \\
\hline 1 & When I shop, I just do it" & 27.70 & 28.30 & 44.00 \\
\hline 2 & "Buy now, think about it later" describes me & 19.00 & 14.10 & 66.90 \\
\hline 3 & I am a bit out of control over what I buy & 25.50 & 13.60 & 60.90 \\
\hline 4 & I usually find great pleasure in shopping & 59.80 & 22.80 & 17.40 \\
\hline 5 & When I see an item, I purchase it because I am reminded of it & 47.90 & 33.70 & 18.40 \\
\hline 6 & I go to malls to check promotions and deals, and end up purchasing them & 25.00 & 29.30 & 45.70 \\
\hline
\end{tabular}

$59.80 \%$ of the respondents agree on having a satisfactory feeling when they shop, $22.8 \%$ is neutral, and $17.40 \%$ disagrees. Having $59.8 \%$ of the respondents state that they find pleasure in shopping, makes sense given the results mentioned before.

Reminder Impulse Buying is the process in which customers' need for an item is triggered when they see this item or are reminded of it (Lee \& Kacen, 2008). Results show that $47.90 \%$ of the respondents purchase an item because they are reminded of it, $33.7 \%$ is neutral, and $18.40 \%$ disagrees on the statement. Therefore, $47.8 \%$ of the responders have Reminder IBB.

The intent to go to the malls to check promotions and deals is called Planned IBB. $25.00 \%$ agrees on the intent to go to the malls to check on offers, $29.3 \%$ is neutral, and $45.70 \%$ disagrees. $25 \%$ of the respondents have Planned IBB, whereas $45.7 \%$ does not have this behavior even if they might be displaying other categories of IBB.

\section{Section 3. Education and Emotional Intelligence}

Previous questions show that the majority of the respondents have a category of IBB or another or a combination. The relation between their habits and their attitudes is yet to be determined; however, results in Table 4 show that $62 \%$ of the respondents do think about the items they are buying, regardless of whether or not they display IBB. $43.5 \%$ of the respondents go shopping depending on how they feel. In terms of Emotional Intelligence, it seems that people with high emotions may resort to the buying habits to relieve their tension. Further correlation need to be done in this regards.

Table 4: Education and Emotional Intelligence

\begin{tabular}{|c|l|c|c|c|}
\hline No. & \multicolumn{1}{|c|}{ Statement } & A & N & D \\
\hline 1 & I consider all types of merchandise before purchasing an item & 62.00 & 19.00 & 19.00 \\
\hline 2 & I go shopping depending on how I feel at the moment & 43.50 & 19.50 & 37.00 \\
\hline 3 & I think about the product's benefits before purchasing it & 81.00 & 13.00 & 06.00 \\
\hline 4 & I analyze every purchase I make & 60.30 & 23.40 & 16.30 \\
\hline 5 & I purchase products based on their value and need to me & 83.70 & 10.90 & 5.40 \\
\hline 6 & I think about the value of each item before purchasing it & 78.90 & 14.10 & 7.00 \\
\hline 7 & Before buying an item, I check if I can afford it & 90.20 & 5.40 & 4.40 \\
\hline 8 & $\begin{array}{c}\text { My purchase is affected by people around me (family, friends, } \\
\text { colleagues) }\end{array}$ & 40.80 & 23.90 & 35.30 \\
\hline 9 & I feel satisfied with my purchase & 80.40 & 16.80 & 2.80 \\
\hline 10 & $\begin{array}{l}\text { The purchases I make are keys to maintaining my self-image and } \\
\text { status }\end{array}$ & 48.40 & 32.10 & 19.50 \\
\hline 11 & I feel in control whenever I am shopping & 60.90 & 23.90 & 15.20 \\
\hline 12 & I regret buying the merchandise I did not intend to buy & 37.00 & 34.80 & 28.20 \\
\hline
\end{tabular}




\begin{tabular}{|c|l|c|c|c|}
\hline 13 & I study each item before buying it & 70.10 & 15.20 & 14.70 \\
\hline 14 & I advise my friends to buy things just for the fun of it & 12.00 & 22.30 & 65.70 \\
\hline 15 & I am in control whenever I am shopping & 72.80 & 16.30 & 10.90 \\
\hline 16 & My buying habits do not get affected by my mood & 47.80 & 21.70 & 30.50 \\
\hline
\end{tabular}

$81.00 \%$ of the respondents agree that they think about the product's benefit before making the purchase. Getting to an $81 \%$ approval on the statement, which is much higher than the $62 \%$ obtained in question 1 , decreases the percentage of respondents who act in answer to their impulse without considering the benefits. The results of this question compared to those of question 1 make us think that Emotional Intelligence has a role in the behavior of the IBB, even though it seems that the majority of the respondents display IBB, and even though some do buy without considering the need of the merchandise; very few are those who buy without reflecting on the benefit of the item for them.

60.3\% (17.9\% Strongly Agree and 42.4\% Agree) of the respondents analyze their purchases before making them. This result conforms to the results of the previous question, where a cumulative $81 \%$ of the respondents usually think about the benefit of the product before the purchase. $83.70 \%$ of the respondents agree that their products' purchase is based on their value to them. This result matches those gained from the previous questions ( 3 and 4 ). A cumulative of $83.7 \%$ agrees that the value of the item limits their purchase, irrespective of their impulsive behavior; a cumulative of $78.90 \%$ thinks about the value of each item before purchasing it. These results also match the ones of the previous questions.

The results of questions 3 through 6 test the ability of the respondents to analyze their purchase according to the latter's value, need and benefits. The results of these questions are somehow identical, leading to the same conclusion; the majority of the respondents do analyze all the aspects of the purchase they make. However, these results contradict previous results concerning respondents' impulsive buying behavior (questions 1-6).

Furthermore, $90.20 \%$ of the respondents agree that before buying an item, they check if they can afford it. These results indicate that impulses are impeded by the cost of the item, which can stop the impulse. $40.80 \%$ agrees on the fact that their purchases are affected by the people around them. These respondents might have a certain Emotional Intelligence in this aspect; they do have an increase in their purchases because they care about the people around them and they make informed decisions of the cost, benefit, and they do consider the purchases. $80.40 \%$ of the respondents are satisfied with their purchases. This high percentage may be related to the impulse buying itself and the evaluation of the purchase, which lead to a satisfaction with the purchase.

Other results show that $48.4 \%$ of the respondents make their purchases to maintain their self-image and status. This high percentage indicates that the purchases made by these respondents are planned and purposeful. $60.90 \%$ of the respondents agree that they feel in control whenever they go shopping. While a cumulative of $15.20 \%$ is not in control whenever they are buying; this indicates a small percentage of people with an impulsive buying behavior. $37 \%$ of the respondents regret buying the merchandise they did not intend to buy. These results contradict with the results of questions 3 to 5 , where the respondents planned and analyzed every purchase made.

Table 4 also shows that $70.1 \%$ of the respondents study each item before buying it. This high percentage indicates that these respondents analyze and explore every item before purchasing it. This result contradicts with that of the previous question. These conflicts lead to a confusion concerning the respondents' understanding of the topic or even the questions. $65.70 \%$ of the respondents do not advise their friends to buy things for the fun of it. This high percentage indicates that the majority of the respondents don't exert a buying influence on their friends and they don't remind them to buy a certain item. $72.80 \%$ agrees that they are in control whenever they are shopping. This result matches that of questions 3 (section 2) and 11 (section 3). Finally, $47.8 \%$ agrees that their buying habits do not get affected by their moods. While a 
cumulative of $30.4 \%$ of the respondents disagree on this matter. However, question 1 (section 1) shows that $49.5 \%$ of the respondents go shopping to change their mood. Thus, these results are inconclusive regarding the effect of the respondents' buying habits and their mood.

\section{Section 4: Demographics}

Results show that $38.59 \%$ of the respondents are males and $61.41 \%$ are females. Also, $69 \%$ of the respondents are single, $26 \%$ married and only 5\% divorced. Moreover, data show that the 18-25 years old is the age group with the most percentage $(30.40 \%)$; the second being $26-30$ years old $(20.70 \%)$; the third 31-35 years old (16.18\%); and, the fourth 36-40 years old (14.70\%). The other six age groups have a total percentage of $17.40 \%$. However, the mean reflects that the majority belongs specifically to the range of 3035 years old with a value of 2.95 . Thus, the majority of the respondents are working adults. This shows that the sample chosen is of a young age. Further, $80.40 \%$ of the respondents have earned undergraduate and graduate degrees (26.60\% Bachelor and 53.30\% Master degrees, respectively), 6.50\% has a High School or lower diploma, and an equal number of respondents $(6.50 \%)$ have either a $\mathrm{PhD}$ or continue to follow their undergraduate studies. As for the respondents' salary ranges, results show that $60 \%$ of the respondents have an annual salary range between $\$ 0$ and $\$ 18,000,10.59 \%$ between $\$ 18,001$ and $\$ 24,000,12.94 \%$ between 24,001 and 36,000 , and $16.47 \%$ more than $\$ 36,000$. Furthermore, results show that $39.90 \%$ of the respondents' primary industry is in general business, $25.10 \%$ engages in engineering, sciences, IT and communications. $22.30 \%$ is in healthcare and education, while $12.70 \%$ of the respondents deal with media, arts, society and logistics. The aforementioned distribution of fields of specialization represent the respondents who learned and studied the most professional courses offered in their schools and institutes which at the same time train the consumers to develop deep understanding of the market, product, brand and utility; this leads to an increase in their awareness and their ability to perform a particular purchase (Khan \& Chawla, 2014).

\section{Results and Findings: Inferential Statistics}

\section{Correlations}
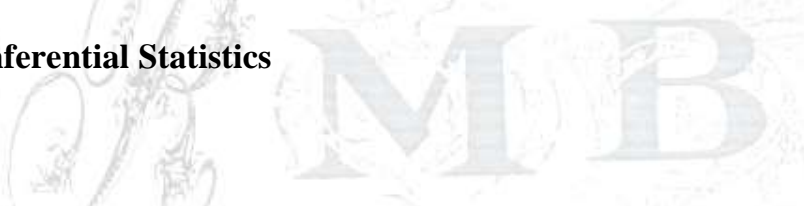

Hejase and Hejase (2013) contend that to study the relationship between two variables a contingency table is to be used; it "is a table used to classify cases according to two identifiable nominal or ordinal measurement characteristics. A contingency table is a cross-tabulation that simultaneously summarizes two variables of interest" (p. 292). Next, several relationships are tested with the purpose of exploring later the necessary causal equations which will help assess the research concepts under study. It is important to mention that only the significant correlations have the complete analysis with Chi-Square tables.

\section{A. Impulsive Buying versus Educational Level}

\section{Crosstab 1: I go shopping to change my mood * Educational level (if applicable)}

Results show that 79 out of $184(42.93 \%)$ respondents who have earned their bachelor degree, their master degree and their doctorate do not go shopping to change their mood. On the other hand, an almost equal number of 81 out of 184 (44\%) respondents do go shopping to change their mood. Results from crosstabulation of both variables show a very small Pearson $\mathrm{R}=0.080$, negligible, and statistically insignificant; $\mathrm{P}=.283>\alpha=0.05$.

\section{Crosstab 2: I feel happy when I buy an item that I didn't plan for * Educational level (if applicable)}

Results show that 105 out of $184(57.1 \%)$ respondents who have earned their bachelor degree, their master degree and their doctorate feel happy when they buy an item that they didn't plan for. On the other hand, 55 out of 184 (29.9\%) respondents do not. While Tables 2 and 3 show that the cross-tabulation of both 
variables show a small Pearson $\mathrm{R}=0.254$, however statistically significant; $\mathrm{P}=.000<\alpha=0.05$. The Chi square test confirms the statistically significant relationship, whereby $\chi^{2}=33.915$ and $\mathrm{P}=.004<\alpha=0.05$.

Table A: Chi-Square tests: Crosstab 2

\begin{tabular}{|l|c|c|c|}
\hline & Value & df & $\begin{array}{c}\text { Asymptotic Significance (2- } \\
\text { sided) }\end{array}$ \\
\hline Pearson Chi-Square & $\mathbf{3 3 . 9 1 5}^{\mathbf{a}}$ & $\mathbf{1 5}$ & $\mathbf{. 0 0 4}$ \\
Likelihood Ratio & 31.454 & 15 & .008 \\
Linear-by-Linear Association & 11.834 & 1 & .001 \\
N of Valid Cases & 184 & & \\
\hline
\end{tabular}

a. 17 cells $(70.8 \%)$ have expected count less than 5 . The minimum expected count is .17.

Table B: Symmetric Measures: Crosstab 2

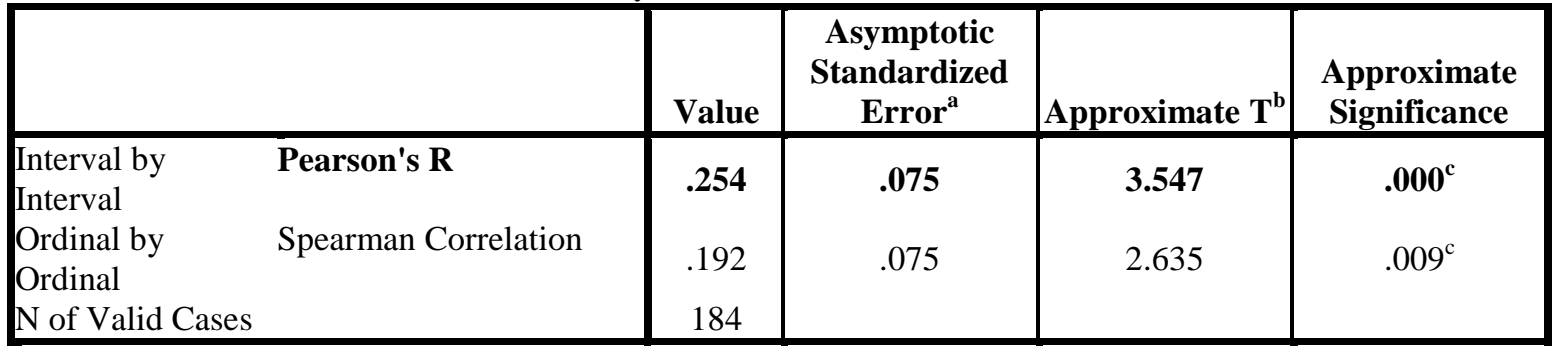

a. Not assuming the null hypothesis.

b. Using the asymptotic standard error assuming the null hypothesis.

c. Based on normal approximation.

\section{Crosstab 3: I regret buying without a plan * Educational level (if applicable)}

Results show that 101 out of $184(54.89 \%)$ respondents who have earned their bachelor degree, their master degree and their doctorate regret buying without a plan. On the other hand, 59 out of 184 (32.1\%) respondents do not. Results from cross-tabulation of both variables show a very small Pearson $\mathrm{R}=-0.082$, negligible, and statistically insignificant; $\mathrm{P}=.270>\alpha=0.05$.

\section{Crosstab 4: I have difficulty controlling my urge to buy when I see a good offer}

* Educational level (if applicable)

Also, 94 out of $184(51.1 \%)$ respondents who have earned their bachelor degree, their master degree and their doctorate do not have difficulty controlling their urge to buy when they see a good offer. On the other hand, 66 out of $184(35.87 \%)$ respondents do. In addition, results from cross-tabulation of both variables show a very small Pearson $\mathrm{R}=-0.131$, negligible, and statistically insignificant; $\mathrm{P}=.076>\alpha=0.05$.

\section{Crosstab 5: When I see a good deal, I tend to buy more than I intended to buy * Educational level (if applicable)}

63 out of $184(34.24 \%)$ respondents who have earned their bachelor degree, their master degree and their doctorate do not buy more than they intended to buy when they see a good deal.

On the other hand, 97 out of $184(52.72 \%)$ respondents do. Moreover, results from cross-tabulation of both variables show a very small Pearson $\mathrm{R}=-0.052$, negligible, and statistically insignificant; $\mathrm{P}=.487>\alpha=$ 0.05 . 


\section{Crosstab 6: I visit the malls * Educational level (if applicable)}

126 out of $184(68.48 \%)$ respondents who have earned their bachelor degree, their master degree and their doctorate visit the malls. On the other hand, few or 34 out of $184(18.48 \%)$ respondents visit malls. Results from cross-tabulation of both variables show a very small Pearson $R=0.025$, negligible, and statistically insignificant; $\mathrm{P}=.737>\alpha=0.05$.

\section{Crosstab 7: I usually plan on buying something and end up with lot of things * Educational Level (if applicable)}

83 out of $184(45.11 \%)$ respondents who have earned their bachelor degree, their master degree and their doctorate usually plan on buying something and end up with lot of things. On the other hand, few or 77 out of $184(41.85 \%)$ respondents do not. Results from cross-tabulation of both variables show a very small Pearson $\mathrm{R}=0.101$, negligible, and statistically insignificant; $\mathrm{P}=.172>\alpha=0.05$.

\section{Crosstab 8: Having enough money is not an issue for me when I go shopping * Educational level (if} applicable)

88 out of $184(47.83 \%)$ respondents who have earned their bachelor degree, their master degree and their doctorate do not agree that having enough money is not an issue for them when they go shopping. On the other hand, few or 72 out of $184(39.13 \%)$ respondents do agree. Results from cross-tabulation of both variables show a very small Pearson $\mathrm{R}=0.094$, negligible, and statistically insignificant; $\mathrm{P}=.204>\alpha=$ 0.05 .

\section{B. Attitude towards impulsive buying versus Educational Level}

Results of this section are gathered as follows: 16 statements that are cross tabulated against the respondents' educational level do not show that there are statistically significant relationships [Sig. P is less than 5\%] neither is the Pearson R, reflecting no relationships [ $R$ negligible] between the different statements that describe the respondents' attitudes towards impulsive buying.

\section{Summary}

Table 5: Crosstabs for Attitude towards Impulsive Buying versus Educational Level

\begin{tabular}{|l|c|c|c|c|}
\hline Statement & Mean & Std. Dev. & R & Sig. P \\
\hline \begin{tabular}{|l|l|l|}
\hline \multicolumn{1}{|c|}{ Section 2 } \\
1. "Just do it" describes my way of shopping
\end{tabular} 2.83 & 1.138 & -.046 & .532 \\
\hline 2. "Buy now think about it later" describes me & 2.36 & 1.171 & .065 & .382 \\
\hline 3. I am a bit out of control about what I buy & 3.32 & .938 & -.081 & .272 \\
\hline 4. I usually find great pleasure in shopping & 2.63 & 1.078 & -.059 & .428 \\
\hline $\begin{array}{l}\text { 5. When I see an item I purchase it because I am reminded } \\
\text { of it }\end{array}$ & $\mathbf{3 . 4 5}$ & $\mathbf{1 . 0 7 2}$ &.- .149 & $\mathbf{. 0 4 4}$ \\
\hline $\begin{array}{l}\text { 6. I go to malls to check promotions and deals, and end up } \\
\text { purchasing them }\end{array}$ & 3.06 & 1.175 & -.096 & .195 \\
\hline $\begin{array}{l}\text { Section 3 } \\
\text { 1. I consider all types of merchandise before purchasing an } \\
\text { item }\end{array}$ & 4.04 & .868 & -.079 & .284 \\
\hline 2. I go shopping depending on how I feel at the moment & 3.56 & 1.034 & -.012 & .870 \\
\hline 3. I think of the product's benefits before purchasing it & 4.13 & .851 & -.014 & .850 \\
\hline 4. I analyze every purchase I make & 4.02 & .888 & .036 & .393 \\
\hline 5. I purchase products based on their value and need to me & 4.26 & .844 & -.048 & .518 \\
\hline
\end{tabular}




\begin{tabular}{|l|c|c|c|c|}
\hline 6. I think about the value of each item before purchasing it & 3.03 & 1.268 & -.014 & .850 \\
\hline 7. Before buying an item, I check if I can afford it & 4.02 & .685 & -.024 & .745 \\
\hline $\begin{array}{l}\text { 8. My purchase is affected by people around me (family, } \\
\text { friends, colleagues) }\end{array}$ & 3.40 & 1.075 & .036 & .632 \\
\hline 9. I feel satisfied with my purchase & 3.54 & 1.016 & -.052 & .480 \\
\hline $\begin{array}{l}\text { 10. The purchases I make are keys to maintaining my self- } \\
\text { image and status }\end{array}$ & 3.11 & 1.026 & -.039 & .603 \\
\hline 11. I feel in control whenever I go shopping & 2.32 & 1.071 & -.042 & .571 \\
\hline 12. I regret buying the merchandise I did not intend to buy & 3.74 & .947 & -.042 & .567 \\
\hline 13. I study each item before buying it & 3.13 & 1.183 & .097 & .191 \\
\hline 14. I advise my friends to buy things just for the fun of it & 2.83 & 1.138 & .014 & .846 \\
\hline 15. I am in control whenever I go shopping & 2.36 & 1.171 & -.061 & .412 \\
\hline 16. My buying habits are not affected by my mood & 3.32 & .938 & -.089 & .230 \\
\hline
\end{tabular}

Table 5 shows that the only aspect of attitude that is correlated to education is the reminder to buy an item when seen. All other statements are not correlated to the education level, and vary one from the other.

\section{Regression Analysis}

Hejase \& Hejase (2013) contend that a "multiple regression model is needed when the researcher faces the scenario where more than one independent variable is causing variations in the dependent variable under study" (p. 478). Therefore, this section aims to test the explanatory variables possible causal relationships which may help analyze impulsive buying behavior. For such purpose, and following the style reported in Hejase, Hamdar, Noureddin, Hejase and Nsouli (2017) to account for the qualitative meaning of the multivariable relationships, "standardized betas models are used, of the form $Y=\beta_{1} X_{1}+\beta_{2} X_{2}+\beta_{3} X_{3}+\beta_{4}$ $\mathrm{X}_{4}+\ldots$... All accepted tested models are qualitatively justified, whereby Pearson R's, R-Square, F-factor (ANOVA), and coefficients (Betas) are statistically significant (psig. $<\alpha=5 \%$ ).

Table 6 is constructed from three SPSS generated tables, namely, the Model Summary, the ANOVA, and the Coefficients Tables. Table 6 shows that causal analysis has led to the generation of two multivariable relationships. The resultant models are generated using Stepwise analysis, whereby independent variables (explanatory variables) are evaluated through several calculation cycles in which all independent variables are assessed based on $95 \%$ statistical certainty. All variables, whose calculated probabilities are greater than the standardized error of 5\%, are excluded.

For the sake of brevity, details needed to justify the statistical significance of all the models follow the same approach used herein to analyze Model " 1 " (Tables 6 \& 7). Results indicate that Model ' 1 ' is qualitatively suitable due to the acceptable values of the coefficient of correlation $(R=0.678)$ and the adjusted coefficient of determination (Adj. $\mathrm{R}^{2}=0.449$ ), respectively; however, the model is also qualitatively acceptable and statistically significant with an associated probability of 0.040 (which is less than $\alpha=0.05)$.

ANOVA testing indicates that the regression equation predicts better than would be expected by chance. The F-value $=42.073$ with an associated probability of Sig P. $=.000<\alpha=5 \%$. Furthermore, Model 1 has all standardized Betas which are statistically significant with probabilities (.000, .001, and .040, all less than the standard error of 5\%). Durban-Watson test's result of approximately 2 show that there is no autocorrelation in residuals of the regression equation. Furthermore, the interpretation of standardized Betas is applied to all explanatory variables as follows: The independent variable " $\mathrm{X}_{1}$ " has a regression standardized weight of " $\beta_{1}$ ". This means that as this variable " $\mathrm{X}_{1}$ ", increases by one standard deviation (SD), the dependent variable "DV" will increase by " $\beta_{1}$ " of a SD. 
Table 6: Regression Models Analysis

\begin{tabular}{|c|c|c|c|c|c|c|c|c|}
\hline Model & $\begin{array}{c}\text { Pearson's } \\
\mathbf{R}\end{array}$ & $\begin{array}{c}\text { Adj. } \\
\mathbf{R}^{2}\end{array}$ & Sig. P & $\mathbf{F}$ & Sig. P & $\begin{array}{c}\text { Standardized } \\
\text { Betas }\end{array}$ & Sig. P & D-W \\
\hline 1 & $.678^{\mathrm{c}}$ & .449 & .040 & 42.073 & $.000^{\mathrm{d}}$ & $\beta_{1}=.542$ & .000 & 1.987 \\
(3 Cycles) & & & & & & $\beta_{2}=.224$ & .001 & \\
& & & & & & $\beta_{3}=.137$ & .040 & \\
\hline 2 & $.746^{\mathrm{f}}$ & .538 & .018 & 30.262 & $.000^{\mathrm{g}}$ & $\beta_{1}=.332$ & .001 & 2.206 \\
& & & & & & $\beta_{2}=.209$ & .000 & \\
& & & & & & $\beta_{3}=-.199$ & .003 & \\
& & & & & & $\beta_{4}=-.200$ & .001 & \\
& & & & & & $\beta_{5}=.197$ & .001 & \\
& & & & & & $\beta_{6}=.139$ & .003 & \\
\hline
\end{tabular}

Table 7: Regression Models

\begin{tabular}{|c|c|c|}
\hline Independent Variable & $\begin{array}{c}\text { Standardized } \\
\text { Betas }\end{array}$ & Dependent Variable \\
\hline $\begin{array}{l}\text { Model 1 } \\
\text { 1- I feel in control when I go shopping }\left(X_{1}\right) \\
\text { 2- I study each item before buying it }\left(X_{2}\right) \\
\text { 3- Before buying an item, I check if I can afford it } \\
\quad\left(X_{3}\right)\end{array}$ & $\begin{array}{l}\beta_{1}=.542 \\
\beta_{2}=.224 \\
\beta_{3}=.137\end{array}$ & $\begin{array}{l}\text { I am in control when I am } \\
\text { shopping }(Y)\end{array}$ \\
\hline $\begin{array}{l}\text { Model } 2 \\
\text { 1- I have difficulty controlling my urge to buy when I } \\
\text { see a good offer }\left(\mathrm{X}_{1}\right) \\
\text { 2- I usually plan on buying something and end up with } \\
\text { lot of things }\left(\mathrm{X}_{2}\right) \\
\text { 3- GPA }\left(\mathrm{X}_{3}\right) \\
\text { 4- I purchase products based on their value and need to } \\
\text { me }\left(\mathrm{X}_{4}\right) \\
\text { 5- "Just do it" describes my way of shopping }\left(\mathrm{X}_{5}\right) \\
\text { 6- I advise my friends to buy things just for the fun of } \\
\text { it }\left(\mathrm{X}_{6}\right)\end{array}$ & $\begin{array}{l}\beta_{1}=.332 \\
\beta_{2}=.209 \\
\beta_{3}=-.199 \\
\beta_{4}=-.200 \\
\beta_{5}=.197 \\
\beta_{6}=.139\end{array}$ & $\begin{array}{l}\text { I am a bit out of control about } \\
\text { what I buy }(Y)\end{array}$ \\
\hline
\end{tabular}

\section{Regression Model One}

Table 7 shows that the three independent variables or "IV" (explanatory variables) have direct relationship with the dependent variable "DV" "I am in control when I go shopping".

IV(1): I feel in control when I go shopping

This direct relation implies that respondents are certain of being in control when they go shopping, and is not only just a feeling of control.

IV(2): I study each item before buying it

This direct relation proves that respondents are in control since they do study their purchases.

IV(3): Before buying an item I check if I can afford it

This direct relation implies that respondents take into consideration the affordability of the items being purchased, thus, putting them in control of their buying habit.

The regression model is:

$$
\begin{gathered}
\mathrm{Y}=0.542 \mathrm{X}_{1}+0.224 \mathrm{X}_{2}+0.137 \mathrm{X}_{3} \\
(.000) \quad(.001)
\end{gathered}
$$




\section{Regression Model Two}

IV(1): I have difficulty controlling my urge to buy when I see a good offer

This direct relation implies that there is a high temptation to lose control when good offers are found.

IV(2): I usually plan on buying something and end up with lot of things

This direct relation confirms the loss of control over buying when they end up buying more than planned.

IV(3): Grade Point Average

This indirect relation could imply that the higher the GPA, the more control one has over his/her buying habits.

IV(4): I purchase products based on their value and need to me

This indirect relation means that the respondents are more in control when they start looking at the added value of the item and their need for it.

IV(5): "Just do it" describes my way of shopping

This direct relation reflects the loss of control over buying; they just simply buy.

IV(6): I advise my friends to buy things just for the fun of it

This direct relation reflects that respondents lose control over their buying habits and affect their surroundings by providing them with tips to go buy just for the fun of it.

Model two results emphasize the fact of being out of control is multi-factorial, dependent (directly or indirectly) to the need of the item, ability to limit purchases, temptation of good offers and effect on surroundings.

The regression model is:

$$
\mathrm{Y}=\underset{(.001)}{0.332 \mathrm{X}_{1}+0.209 \mathrm{X}_{2}-0.199 \mathrm{X}_{3}+0.200 \mathrm{X}_{4}+\underset{000)}{0.003)}(.001) \quad(.001)}
$$

\section{Reliability Test}

The Internal Reliability of the 22-item scale is assessed using the Cronbach's Alpha technique. Table 8 shows that the 22-item scale produced a Cronbach's Alpha $=0.670$, which belongs to the range 0.6 to $<0.7$ "Moderate" and acceptable in exploratory research" (Burns and Burns, 2008, p. 481). This indicates a good strength of association and proves that the selection of the questions is suitable for the questionnaire purpose.

Table 8: Reliability Statistics

\begin{tabular}{|c|c|}
\hline Cronbach's Alpha & N of Items \\
\hline .670 & 22 \\
\hline
\end{tabular}

\section{Conclusions and Recommendations}

This paper has shed light on consumers' impulsive buying behavior, its types, and factors affecting it. This research topic have its limitations given the fact of lack of literature, and that it has not been studied in the region. Ergo, the conclusions and implications stated herein are not conclusive, especially that the target population study is limited to 184 (not representative of the Lebanese population). However, the results 
shown in this research interestingly open chances for more advanced and in-depth researches that could be completed in the future.

Impulsive buying is when consumers' experience a sudden, powerful, and persistent urge to buy something immediately. "The impulse to buy is hedonically complex and may stimulate emotional conflict. Also, impulsive buying is prone to occur with diminished regards for its consequence" (Rook, 1987, p. 191).

Rook (1983) identified five crucial elements in impulsive buying:

- $\quad$ a sudden and spontaneous desire to act

- a state of psychological disequilibrium

- $\quad$ the onset of psychological conflict and struggle

- a reduction in cognitive evaluation

- a lack of regard for the consequences of impulse buying

Several researches have classified and enumerated the factors that affect impulse buying behavior.

\section{Conclusions}

Impulsive buying behavior has been found to be dependent on demographic factors such as age, gender and GPA. This research gives a general confirmation that the Lebanese population has an impulse buying behavior, more specifically the Reminder Buying type.

This paper has several concepts to explore, test and assess, namely:

\section{1- How does the level of education affect the consumers' impulsive buying behavior?}

Analysis of the correlations of impulsive buying versus educational level shows that there is no impact of education on impulse buying. This result confirms findings by Sharma \& Kaur (2015) whose Chi squared test reveals that education has no significant relationship with impulsive buying behavior. However, this is in contrast to Bashar, Ahmad \& Wasi (2012) who determined the correlation of consumers' demographic factors on the impulse buying behavior with respect to a number of single impulsivity indicators and one collective indicator. Educational qualification produced a marginal association with impulsive buying behavior.

However, the only significant relation found in this research is the feeling of happiness when buying an item that wasn't intended. In fact, $57 \%$ of the respondents who have earned their BS, MS, and $\mathrm{PhD}$ feel happy when they acquire an unplanned item. Analyzing attitude towards impulsive buying behavior versus educational level show non-significant impact of education on impulsive buying behavior. However, it confirms that $40.76 \%$ of the educated people are classified as Reminder Impulsive Buyers.

\section{2- What is Emotional Intelligence? And how does it affect IBB?}

Emotional Intelligence by definition is "the capacity to be aware of, control, and express one's emotions, and to handle interpersonal relationships judiciously and empathetically" (Goleman, 1995).

The domains of Emotional intelligence are:

- Knowing one's emotions

- Managing own emotions

- Recognizing and knowing others' emotions

- $\quad$ Managing the emotions of others 
- $\quad$ Motivate self

This paper addresses Emotional Intelligence in the aspect of self-motivation through shopping/impulsive buying, while the persons recognize their own emotions as being low and try to compensate. $62 \%$ of the respondents do consider all types of merchandise before purchasing them, and $81 \%$ of the respondents think of the products' benefits before buying them. In addition, $83.7 \%$ purchases their products based on their needs; and, they think about what they are purchasing. These results show that impulses of buying are controlled by the buyers especially when it comes to affordability ( $90.2 \%$ of the respondents). A minority of the respondents agree on the statements that address the mood's influence on IBB; they do not feel that they go shopping as a trigger for motivation when they feel low. Correlations show however that there is a significant relation of the impact of unintended purchases on the respondents: they do feel happy when they buy something not planned for. Here, Faber \& O'Guinn (1992, p. 155) contend that the impulsive buying is "a response to an uncontrollable drive or experience a feeling", while Žnideršić, Grubor, \& Marić (2014) describe such happiness as the customers' deviation from standard and rational behavior to satisfy their physiological and personal psychological needs.

\section{3- How is the Lebanese consumers' IBB affected by the aforementioned factors?}

Regression analysis of all the components of the questionnaire couldn't show a direct link or impact. It did not add any value to the analysis on culture, mood, and emotions. However, it highlighted two major relations:

- Consumers are in control whenever they go shopping, to the extent that they think of the value of the item and check its affordability before purchasing it.

- There is a positive relationship of not being in control and being impulsive because of the impact of the store environment (good offer, promotions and sales...). This argument conforms to the influence of external impulsive purchase factors which are fully controlled by companies to provoke the impulsive buying mechanism as asserted by the following researchers Chen (2008, p. 155), Karbasivar \& Yarahmadi (2011, p. 175), Yang, Huang, \& Feng (2011, p. 275), and Gaurav \& Sahu (2017).

- Impulsiveness is also shown in buying more than planned, just doing the shopping and being impulsive, and affecting others with one's behavior while advising them of buying items just for the fun of it. At the same time, this impulse is limited (negative relation) by the GPA (reverse relation; when the GPA is high, the impulse decreases) and when the buyer considers the value and the need of the item (the impulse decreases when the value of the item is in question).

In this case, in addition to the aforementioned researchers, Maricić (2011, p. 133) contend that affects reflect the consumers' immediate and automatic response to stimulias delineated herein:

- $\quad$ Mood and emotions

- $\quad$ Trait buying impulsiveness

- Culture

- $\quad$ Store environment

- Consumer's income

- Demographic factors.

This paper elaborates on the following:

1- The correlation between mood and emotions on IBB is inconclusive; a more detailed research needs to be done with a larger population sample.

2- There is an obvious buying impulsiveness trait in the population under study - Reminder Impulsive Buying that is related to the education level. Further studies might shed light on the why; however, at this point of the study, it is not clear why educated people forget what they want to buy and are reminded when they see the item. 
3- The Lebanese cultural impact on IBB is interesting to be studied; the results of this research do not specify the impact and make it interesting to study more.

4- The store environment was not addressed in details in the questionnaire; however, there is a clear impact of the display of items in the store that affect the respondents (buying more when they see good offers and buying more than what is planned). This aspect of the study can also be further expanded to see the correlation with the IBB.

5- Consumers' income is not analyzed in depth; however, it has been shown that the majority of the respondents have a yearly income of maximum 18,000\$. The interesting aspect that showed increased answers is that the respondents study and consider the items for affordability and value before they make the purchase. And the regression Model 2 show that the consideration of the item's value decreases the impulse of buying.

6- Demographic factors are not all taken in the analysis; the focus of this research is to see the education level over IBB. It shows that there is a positive correlation with the level of education and the Reminder IBB (as stated above). It is also shown in the regression analysis that there is a reverse relation between the GPA and the IBB.

\section{Future Researches}

Given the above mentioned, many topics can be further studied, such as:

1- Expansion of the same research to include a bigger sample of the Lebanese population living in Lebanon

2- Expansion of the same research to include a sample of the Lebanese population living abroad

3- Gender effect over IBB in the Lebanese population

4- Lebanese cultural effect over the IBB - in correlation with the gender or in general.

5- Lebanese income's effect on IBB

6- What traits of impulsiveness the Lebanese population have and the reasons for them

7- Impact of the mood and emotions on the IBB and effect of the IBB on the mood and emotions

8- Education level and specialty impact on IBB in the Lebanese population

All the above mentioned topics can be studied in the Region as well.

This research has apparent attributes manifested in being the first academic and parametric research performed in Lebanon relevant to “Consumers' Impulsive Buying Behavior". Consequently, the findings in this paper add new insights into the body of knowledge of consumer behavior in the Middle East, inciting other researchers to carry out comparative studies needed to construct a general assessment of the topic in the region. 'Consumers' Impulsive Buying Behavior' is an attractive old and new and rather important concept treated worldwide; as such, it is necessary to have a better awareness of it in countries such as Lebanon, where the customer's worth is not fully appreciated, and the 'buying behavior' concept is not comprehensively understood. Though this paper empirical analysis provided actual facts, the findings may not be generalized because of the convenience sampling and limited number of participants. Regardless of such limitations, this research does offer an indispensable insight into and contribution to the assessment and understanding of the Lebanese consumer and what triggers his/her buying impulsiveness. Findings of this research may bring new insights to marketers in their quest to construct successful marketing and advertising campaigns.

\section{Acknowledgement}

The authors would like to acknowledge the constructive criticism and editing performed by Mrs. Henriette Skaff, senior editor at the American University of Science and Technology's Publications Department. 


\section{References}

Abratt, R., \& Goodey, S. (1990). Unplanned Buying and In-store Stimuli in Supermarkets. Manegerial and Desicion Economics, 111- 121.

Agee, T., \& Martin, B. (2001). Planned or Impulse Purchases? How to Create Effective Infomercials. Journal of Advertising Research, 35-42.

Awan, A. G., \& Abbas, N. (2015). Impact of Demographic Factors on Impulse Buying Behavior of Consumers in Multan-Pakistan. European Journal of Business and Management, 96-105.

Awan, Hassan, \& Shahid. (2014). Relationship between employees' motivation and customer Satisfaction. Global Journal of Human Resource Management, 1-12.

Bashar, A., Ahmad, I., \& Wasi, M. (2012). A Study of Influence of Demographic Factors on Consumer Impulsive Buying Behaviour. International Journal of Management and Stategy, 1-17.

Bashir, S., Zeeshan, M., Sabbar, A., Hussain, R., \& Sarki, I. (2013). Impact of Cultural Values and Life Style on Impulse Buying Behavior: A Case Study of Pakistan. International Review of Management and Business Research, 2(1), 193-200.

Beautty, S., \& Ferrell, M. (1998). Impulse Buying: Modeling its precursors. Journal of Retailing, 169-191.

Bell, D., Crosten, D., \& Knox, G. (2011). From Point of Purchase to Path to Purchase: How Preshopping Factors Drive Unplanned Buying . Journal of Marketing , 31-45.

Bellenger, D., Robertson, D., \& Hirschman, E. (1978). Impulse Buying Varies by Product. Journal of Advertising Research, 15-18.

Bhojanna, U., \& Raturi, G. (n.d.). Impulse Buying at Retail Stores - Facts Unveiled. ELK Asia Pacific Journals.

Burns, R.B., \& Burns, R.A. (2008). Business Research Methods and Statistics Using SPSS. London: SAGE Publications Ltd.

Bressolles, G., Durrieu, F., \& Giraud, M. (2007). The Impact of Electronic Service Quality's Dimensions on Customer Satisfaction and Buying Impulse. Journal of Customer Behaviour, 37-56.

Bruyneel, S., Dewitte, S., Vohs, K., \& Warlop, L. (2006). Repeated Choosing Increases Susceptibility to Affective Product Features. International Journal of Research in Marketing, 215-225.

Bryman, A. (2012). Social Research Methods (5th ed.). Oxford: Oxford University Press.

Chen, T. (2008). Impulsive Purchase Varied by Products and Marketing Channels. Journal of International Management Studies, 3(1), 154-161.

CIA (2018a). Lebanon Economy 2018 - CIA World Factbook. Retrieved August 12, 2018, from https://theodora.com/wfbcurrent/lebanon/lebanon_economy.html

CIA (2018b). Lebanon Economy 2018 - CIA World Factbook. Retrieved August 27, 2018, from https://www.cia.gov/library/publications/the-world-factbook/geos/print_le.html

Coley, A., \& Burgess, B. (2003). Gender Differences in Cognitive and Affective Impulse Buying. Journal of Fashion Marketing and Management, 7(3), 282-295.

Design, F. (2002-2015). Usability glossary: survey. Retrieved April 30, 2018, from Usability first: http://www.usabilityfirst.com/usability-methods/surveys

Ekeng, A. B., Lifu, F. L., \& Asinya, F. A. (2012). Effect of Demographic Characteristics on Consumer Impulse Buying Among Consumers of Calabar Municipality, Cross River State. Academic Research International, 568-574.

Etzioni, A. (1999). Normative-Affective Factors: Toward a New Decision-Making Model. Journal of Economic Psychology, 91-119.

Faber, R., \& O'Guinn, T. (1992). A Clinical Screening for Compulsive Buying. Journal of Consumer Research, 19(3), 459-469.

Ferber, R. (1973). Consumer Economics, a Survey. Journal of Economic Literature, 1303-1342.

Flick, U. (2011). Introducing Research Methodology: A Beginner's Guide to Doing a Research Project. London: Sage.

Gaurav, K., \& Sahu, K. C. (2017). Demographical Influence on Consumer Buying: An Emperical Investigation. Journal of Modern Management and Entrepreneurship, 7(4), 160-164. 
globaleEDGE. (1994-2017). globaleEDGE. Retrieved May 01, 2018, from https://globaledge.msu.edu/countries/lebanon

Goddard, W., \& Melville, S. (2004). Research Methodology: An Introduction (2nd ed.). Oxford: Blackwell Publishing.

Han, Y., Morgan, G., Kotsiopulos, A., \& Kang, P. (1991). Impulse buying Behavior of Apparel Purchases. Clothing and Textile Research Journal, 15-21.

Hanna, N., \& Wozniak, R. (2001). Consumer Behavior. Prentice - Hall.

Heilman, C., Nakamoto, K., \& Rao, A. (2002). Pleasant Surprises: Consumer Response to Unexpected Instore Coupons. Journal of Marketing Research, 39(May), 242-252.

Hejase, H. J., Hamdar, B., Noureddin, M., Hejase, A. J., \& Nsouli, F. (2017). Assessment of the Relationship between Managers' Emotional Intelligence and Employees' Motivation. The Journal of Middle East and North Africa Sciences, 3(4), 27-47

Hejase, A. J., \& Hejase, H. J. (2013). Research Methods a Practical Approach for Business Students. (2 ${ }^{\text {nd }}$ edn), Philadelphia, PA, USA: Masadir Inc.

Hejase, H. J., \& Alaeddine, A., H. (2017). Fostering Academic Relations between Lebanon and the Islamic Republic of Iran. The Journal of Middle East and North Africa Sciences, 3(7), 22-38.

Howlett, E., Kees, J., \& Kemp, E. (2008). The role of self-regulation, future orientation, and financial knowledge in long-term financial decisions. Journal of Consumer Affairs, 223-242.

Hugar, L., \& Kumar, H. V. (1996). Dynamics of Consumer Behavior in Vegetable Marketing. The Bihar Journal of Agriculture Marketing, 345-351.

Kacen, J., \& Lee, J. (2002). The Influence of Culture on Consumer Buying Behaviour. Journal of Consumer Psychology, 163-176.

Karbasivar, A., \& Yarahmadi, H. (2011). Evaluating Effective Factors on Consumer Impulsive Buying Behavior. Asian Journal of Business Management Studies, 2(4), 174-181.

Karbasivar, A., \& Yarahmadi, H. (2011). Evaluating Effective Factors on Consumer Impulsive Buying Behavior. Asian Journal of Business Management Studies, 2(4), 174-184.

Kelley, K., Clark, B., Brown, V., \& Sitzia, J. (2003). Good Practice in the Conduct and Reporting of Survey Research. International Journal for Quality in Health Care, 15(3), 261-266.

Khan, S. F., \& Chawla, C. (2014). Impact of Education \& Income on Impulsive Buying from Organized \& Unorganized Retail Store. World Journal of Pharmacy and Pharmaceutical Sciences, 1294-1305.

Kidwell, B., Hardesty, D., Murtha, B., \& Sheng, S. (2011). Emotional Intelligence in Marketing Exchanges. Journal of Marketing, 78-95.

Lee, J., \& Kacen, J. (2008). Cultural Influences on Consumer Satisfaction with Impulse and Planned Purchase Decisions. Journal of Business Research, 265-272.

Lee, S., \& Mysky, A. (2004). The Medicalization of Compulsive Buying. Social Science and Medecine, 58, 1709-1718.

Madhavaram, S., \& Laverie, D. (2004). Exploring Impulse Purchasing on the Internet. Advances in Consumer Research, 59-66.

Mai, Lantz, J., \& Loeb, S. (2003). An Exploratory Investigation into Impulse Buying Behaviour in a Transitional Economy: A Study of Urban Consumers in Vietnam. Journal of International Marketing, 13-35.

Malhorta, K. (1996). Marketing Research, an Applied Orientation (2nd ed.). New Jersy: Prentice Hall International.

Manzur, E., Olavarrieta, S., Hidalgo, P., Farías, P., \& Uribe, R. (2011). Store Brand and National Brand Promotion Attitudes Antecedents. Journal of Business Research, 286-291.

Mariciić, B. (2011). Consumer Behavior. Belgrade: The Publishing Center of the Faculty of Economics.

Masouleh, S. E., Pazhang, M., \& Moradi, J. S. (2012). What is Impulsive Buying? An analytical network processing framework for prioritizing factors affecting impulse buying. Management Science Letters, 1053-1064.

Mihic, M., \& Kursan, I. (2010). Assessing the Situational Factors and Impulsive Buying Behavior: Market Segmentation Approach. Management, 15(2), 47-66. 
Mkahal, M. (2016). Organizational Change and Employee Readiness. Beirut, Lebanon: Unpublished Research Project.

Nadeem, H., Akmal, M., Omar, S., \& Mumtaz, A. (2016). Impact of Gender, Education and Age on impulsive Buying: Moderation Role of Consumer Emotional Intelligence. International Journal of Transformation in Operational \& Marketing Management, 1-14.

Park, W., Iyer, E., \& Smith, D. (1989). The effect of situation factors on In-Store grocery shopping behaviour. The Journal of Consumer Research, 422-433.

Prashar, S., Adeshwar, R., Parasaran, V., \& Venna, V. (2015). Factors Prompting Impulsive Buying Behavior: Shopers in Dubai. East Asian Journal of Business Management, 5(3), 5-15.

Rana, S., \& Tirthani, J. (2012). Effect of Education, Income and Gender on Impulsive Buying Among Indian Consumer an Empirical Study of Readymade Garment Customers. Indian Journal of Applied Research, 145-146.

Rook, D. (1987). The Buying Impulse. Journal of Commerce Research, 189-199.

Rook, D., \& Fisher, R. (1995). Normative Influences on Impulsive Buying Behaviour. The Journal of Consumer Research, 305-313.

Rook, D., \& Gardener, M. (1993). In the Mood: Impulse Buying's Affective Antecedents. Research in Consumer Behaviour, 1-28.

Sarki, I. H., Bhutto, N. A., Arshad, I., \& Khuhno, R. (2012). Impact of Pakistani University Students' Cultural Values and Lifestyles on Meaning Brands. Interdisciplinary Journal of Contemporary Research in Business, 39(9), 643-654.

Saunders, M., Lewis, P., \& Thornhill, A. (2007). Research Methods for Business Students. Pearson Education.

Shahjehan, A., Qureshi, J. A., Zeb, F., \& Saifullah, K. (2012). The effect of personality on impuulsive and compulsive buying behaviors. African Journal of Business Management, 2187-2194.

Sharma, K. C., \& Kaur, S. (2015). The Impact of Demographic Factors on Impulse Buying Behaviour of Online and Offline Consumers (A case sutdy of Punjab, Haryana, New Delhi and Chandigarh). International Journal of Engineering Technology, Management and Applied Sciences, 9(3), 63-69.

Silvera, D., Lavack, A., \& Kropp, F. (2008). Impulse Buying: The Role of Affect, Social Influence, and Subjective Wellbeing. Journal of Consumer Marketing, 25(1), 23-33.

Solomon, M. R. (2002). Consumer Behavior. Prentice-Hall.

Tice, D., Bratslavsky, E., \& Baumeister, R. (2001). Emotional Distress Regulation Takes Precedence over impulse control. Journal of Personality and Social Psychology, 53-67.

Unicef. (2013). At a Glance: Lebanon. Unicef. Retrieved from https://www.unicef.org/infobycountry/lebanon_statistics.html

Verplanken, B., \& Sato, A. (2011). The Psychology of impulse buying: An integrative self-regulation approach. Journal of Consumer Policy, 197-210.

Vohs, K., \& Faber, R. (2007). Spent Resources: Self-Regulatory Resource Affects Impulse Buying. Journal of Consumer Research, 33(4), 537-547.

Weinberg, P., \& Gottwald, W. (1982). Impulsive Consumer Buying as a Result of Emotions. Journal of Business Research, 43-57.

Wood, M. (1998). Socioeconomic Status, Delay of Gratification and Impulse Buying. Journal of Economic Psychology, 295-320.

Workman, L., \& Paper, D. (2010). Compulsive Buying: A Theoretical Framework. The Journal of Business Inquiry, 9(1), 89-126.

Xiofang, Z., \& Miller, C. (2003). Examinations of Measurements of Emotional Intelligence. Ergometrika, 38-49.

Yaacoub, N., \& Badre, L. (2012). Education in Lebanon, Statistics in Focus. Central Administration of Statistics(3).

Yang, D. J., Huang, K., \& Feng, X. (2011). A Study of the Factors that Affect the Impulsive Cosmetics Buying of Female Consumers in Koahsiung. International Journal of Business and Social Science, 2(24), 275-282. 
Yeboah, A., \& Prempeh, V. O. (2017). Exploring the Consumer Impulsive Buying Behaviour from a Range of Consumer and Product Related Factors. International Journal of Marketing Studies, 9(2), 146-159.

Youn, S., \& Faber, R. (2000). Impulse Buying: Its Relation to Personality Traits and Cues. NA Advencesin Consumer Research, 27, 179-185.

Žnideršić, R. K., Grubor, A., \& Marić, D. (2014). Impulsive Consumer Behavior. International Journal of Multidisciplinarity in Business and Science, 2(2), 81-89. 